In Retrospect

\title{
Forty years of linking orbits to ice ages
}

In 1976, it was demonstrated that tiny wobbles in Earth's orbit led to the great ice age cycles of the past few million years. This finding had wide implications for climate science and the details remain hotly debated today.

Mark Maslin

Forty years ago, Hays, Imbrie and Shackleton ${ }^{1}$ published one of the most influential papers in the study of Earth's past climate. The authors showed that variations in Earth's orbital path around the Sun were the pacemaker of the great ice ages in the Quaternary Period (the current geological period, which began about 2.6 million years ago). This study is a beautiful example of how three exceptional scientists together robustly tested a controversial theory. They confirmed what is now known as the Milankovitch theory ${ }^{2}$ allowing us to understand the fundamental causes of the great ice ages and to peer into the future to see if humanity has broken these natural cycles.

Milutin Milankovitch was a brilliant Serbian mathematician and climatologist, who in 1941, postulated that wobbles in Earth's orbit changed the distribution of solar energy on the planet's surface, pushing Earth in or out of an ice age ${ }^{2}$ - a process called orbital forcing. He suggested that insolation (the amount of incoming solar radiation) at a latitude of $65^{\circ} \mathrm{N}$, just south of the Arctic Circle, was critical. At this latitude, insolation can vary by $25 \%$ (from 430 to 560 watts per square metre $)^{1,2}$. Milankovitch argued that when insolation was reduced during the summer, some of the ice in this region could survive. Each year, the ice would build up to eventually produce an ice sheet. 
In 1976, three gifted scientists joined forces to test Milankovich's theory, using long-term climate records that were obtained by analysing marine sediments. Jim Hays founded and led the international CLIMAP project ${ }^{3}$, which used fossil assemblages to estimate past sea surface temperatures and brought the dream team together. Nick Shackleton was the master of stratigraphy and provided oxygen isotope records, which showed past global ice volumes. Finally, John Imbrie was the expert in time-series analysis, particularly spectral analysis, which showed that the climate records matched calculations of high-latitude insolation. Remarkably, the authors discovered that these records contained the same temporal cycles as three parameters that describe Earth's orbit: eccentricity, obliquity and precession (Fig. 1).

Eccentricity describes the shape of Earth's orbit around the Sun, which varies from nearly a circle to an ellipse, in part because of Jupiter's gravity. Obliquity is the tilt of Earth's axis of rotation with respect to the plane of its orbit, which directly affects the intensity of the seasons. Finally, precession is the most complicated type of variation because it alters the distance between Earth and the Sun during each season, and has two components - Earth's rotational axis precesses (rotates) due to tidal forces exerted by the Sun and the Moon on the solid Earth, and Earth's orbital path itself precesses around the Sun.

By demonstrating the clear link between orbital forcing and Earth's past climate, Hays, Imbrie and Shackleton legitimized what was to become one of the most powerful tools in stratigraphy. For example, reliable and comparable age models can be constructed for past climate records for at least the past 5 million years by tuning the orbital parameters to the ice age cycles ${ }^{4}$. Such age models can be applied to any long palaeoclimate record, allowing marine and land records to be compared.

Additionally, the different effects of the three orbital parameters have been used to study orbital forcing at different latitudes. Obliquity has a strong influence at high latitudes, whereas 
precession has a significant impact on seasonality in the tropics - precession has been linked to the rise and fall of the African rift valley lakes, and even our own evolution ${ }^{5}$. Evidence for the orbital forcing of climate has now been found as far back as 1.4 billion years ago, in the Proterozoic eon ${ }^{6}$.

Hays, Imbrie and Shackleton clearly set out the limitations of their study and posed challenges to the scientific community, many of which still remain today. In particular, the authors recognized that variations in the orbital parameters did not cause the ice age cycles but rather paced them. Any given combination of parameters can be associated with many different climates — for example, we have a similar orbital configuration today as 18,000 years ago when there was a 3kilometre-thick ice sheet sitting on North America ${ }^{1}$. Feedback mechanisms take the small changes in insolation driven by the orbital parameters and push the Earth into or out of an ice age. Therefore, the next step was to understand the relative importance of ice sheet, ocean and atmospheric feedbacks, which led to the discovery that greenhouse gases had a pivotal role in controlling past climate.

The authors' work also recognized the so-called ‘100,000-year' problem. Before 1 million years ago, ice ages occurred roughly every 41,000 years due to variations in Earth's obliquity ${ }^{7}$. This makes climatological sense because the tilt of the Earth directly controls how warm or cold the summers are in the Northern Hemisphere. But the last eight ice age cycles had a longer period of 100,000 years $^{8}$, which is similar to the period associated with eccentricity. In terms of forcing, eccentricity is by far the weakest of the three orbital parameters, which would suggest some complicated 'nonlinear' amplification affect by the Earth's climate system.

However, the similarity between the two periods turned out to be an artefact of spectral analysis $^{7}$ — although the last eight ice age cycles lasted for about 100,000 years on average, they ranged in length from 80,000 to 120,000 years. With the realisation that eccentricity is not the major driving force, a debate has emerged as to whether precession or obliquity controlled the timing of 
the most-recent ice age cycles. Some argue that deglaciations occurred every four or five precessional cycle ${ }^{7,8}$, others suggest it is every second or third obliquity cycle ${ }^{9}$ and some argue it is a combination of both ${ }^{10}$. The debate started 40 years ago and still rages today.

The authors' work also provides us with a tool to investigate the future of Milankovitch cycles. It has been suggested that small increases in greenhouse gases due to the expansion of agriculture that started 8,000 years ago ${ }^{11}$ have in fact delayed the next ice age ${ }^{12}$. Moreover, if our greenhouse gas emissions continue to grow, we might have put off the next ice age for at least half a million years ${ }^{13}$. Understanding orbital forcing is therefore relevant to contemporary debates about the Anthropocene - a proposed geological Epoch that is shaped by human activity. If we have merely delayed the next ice age, we will still be in the Quaternary Period and the Anthropocene can be defined as an Epoch. But if we have stopped the ice ages, we will have entered the Anthropocene Period ${ }^{14}$, marking a larger change in the Earth System. Hence understanding the causes of the great ice ages is central to both understanding the past and our future.

Mark Maslin is in the Department of Geography, University College London, London WC1E 6BT, UK.

e-mail:m.maslin@ucl.ac.uk

1. Hays, J. D., Imbrie, J. \& Shackleton, N. J. Science 194, 1121-1132 (1976).

2. Milanković, M. M. Canon of Insolation and the Ice-Age Problem (Koniglich Serbische Academie, 1941).

3. CLIMAP. Geol. Soc. Am. Map Chart Ser. MC-36 (1981).

4. Lisiecki, L. E. \& Raymo, M. E. Paleoceanography 20, PA1003 (2005).

5. Maslin M. A. et al. Quaternary Science Reviews 101, 1-17 (2014). 
6. Zhang, S. et al. Proc. Natl. Acad. Sci. vol. 112 no. 12 E1406-E1413 (2015).

7. Maslin, M. A. \& Brierley, C. Quaternary International 389, 47-55 (2015).

8. Ridgwell, A., Watson, A. \& Raymo, M. Paleoceanography 14, 437-440 (1999).

9. Huybers, P. J. Nature 480, 229-232 (2011).

10. Huybers, P. \& Wunsch, C. Nature 434, 491-494 (2005).

11. Ruddiman, W. F. Climatic Change 61, 261-293 (2003).

12. Tzedakis, P. C., Channell, J. E. T., Hodell, D. A., Kleiven, H. F. \& Skinner, L. C. Nature Geoscience 5, 138-141 (2012).

13. Archer, D. \& Ganopolski, A. Geochem. Geophys. Geosyst. 6, Q05003 (2005).

14. Lewis, S. L. \& Maslin, M. A. Nature 519, 171-180 (2015).

a Eccentricity

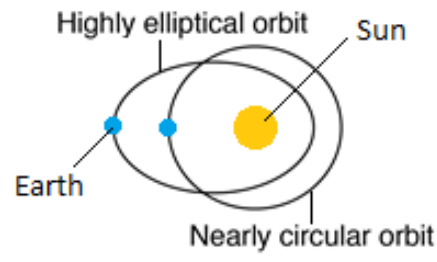

b Obliquity

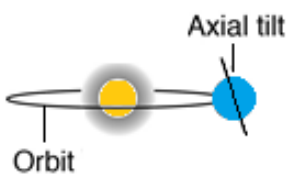

c Precession

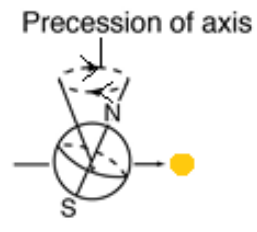

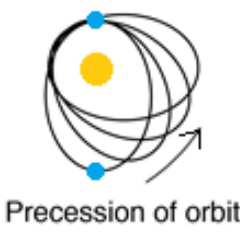

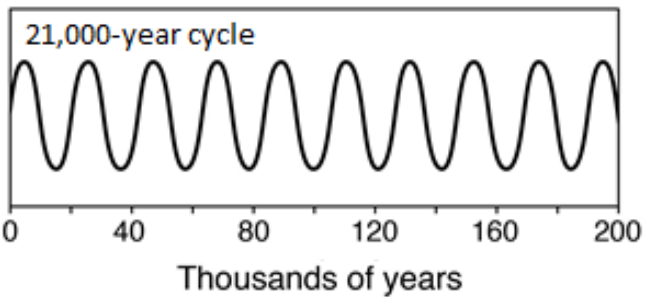

Figure 1 | Milankovitch cycles. In 1976, Hays, Imbrie and Shackleton ${ }^{1}$ provided the first clear 
evidence that variations in Earth's orbit around the Sun dramatically change our planet's climate, a concept known as the Milankovitch theory ${ }^{2}$. There are three types of variation: eccentricity, obliquity and precession ${ }^{1,2}$. a, Eccentricity describes the shape of Earth's orbit around the Sun, which varies from nearly a circle to an ellipse with a period of about 96,000 years ${ }^{7} . \mathbf{b}$, Obliquity is the tilt of Earth's axis of rotation with respect to the plane of its orbit, which oscillates with a period of about 41,000 years ${ }^{7,9}$. c, Both Earth's rotational axis and orbital path precess (rotate) over time — the combined effects of these two components and the eccentricity produce an approximately 21,000-year cycle . $^{7,8}$. 